\title{
Impact of Surface Modification and Nanoparticle on Sisal Fiber Reinforced Polypropylene Nanocomposites
}

\author{
Idowu David Ibrahim, ${ }^{1}$ Tamba Jamiru, ${ }^{1}$ Emmanuel Rotimi Sadiku, ${ }^{2}$ \\ Williams Kehinde Kupolati, ${ }^{3}$ and Stephen Chinenyeze Agwuncha ${ }^{2}$ \\ ${ }^{1}$ Department of Mechanical Engineering, Tshwane University of Technology, Pretoria, South Africa \\ ${ }^{2}$ Polymer Section, Department of Chemical Metallurgy and Materials Engineering, Tshwane University of Technology, \\ Pretoria, South Africa \\ ${ }^{3}$ Department of Civil Engineering, Tshwane University of Technology, Pretoria, South Africa
}

Correspondence should be addressed to Idowu David Ibrahim; ibrahimid@tut.ac.za

Received 4 June 2016; Revised 30 August 2016; Accepted 14 September 2016

Academic Editor: Simon Joseph Antony

\begin{abstract}
Copyright (C) 2016 Idowu David Ibrahim et al. This is an open access article distributed under the Creative Commons Attribution License, which permits unrestricted use, distribution, and reproduction in any medium, provided the original work is properly cited.

The use of plant fibers, polymer, and nanoparticles for composite has gained global attention, especially in the packaging, automobile, aviation, building, and construction industries. Nanocomposites materials are currently in use as a replacement for traditional materials due to their superior properties, such as high strength-to-weight ratio, cost effectiveness, and environmental friendliness. Sisal fiber (SF) was treated with $5 \% \mathrm{NaOH}$ for 2 hours at $70^{\circ} \mathrm{C}$. A mixed blend of sisal fiber and recycled polypropylene (rPP) was produced at four different fiber loadings: 10, 20, 30, and $40 \mathrm{wt} . \%$, while nanoclay was added at 1, 3, and 5 wt. $\%$. Maleic anhydride grafted polypropylene (MAPP) was used as the compatibilizer for all composites prepared except the untreated sisal fibers. The characterization results showed that the fiber treatment, addition of MAPP, and nanoclay improved the mechanical properties and thermal stability and reduced water absorption of the SF/rPP nanocomposites. The tensile strength, tensile modulus, and impact strength increased by $32.80,37.62$, and $5.48 \%$, respectively, when compared to the untreated SF/rPP composites. Water absorption was reduced due to the treatment of fiber and the incorporation of MAPP and nanoclay.
\end{abstract}

\section{Introduction}

The use of natural fibers as reinforcement in polymeric composites has attracted a lot of attention, especially in the building, aviation, and automobile industries [1]. Utilization of natural fibers is gradually facing out the use of nonbiodegradable synthetic fibers such as E-glass and S-glass, currently used as reinforcement in polymeric composites. Natural fibers seem to be a prominent replacement because of their advantages, which include low density, high strengthto-weight ratio, biodegradability, environmental friendliness, renewability, and low cost [2-5]. Tables 1 and 2, respectively, show the chemical composition and the mechanical properties of some natural fibers. Polymer-based composites containing reinforcement and/or fillers are extremely advantageous because they give rise to toughness and strength greater than those of the unreinforced materials [6]. The chemical and physical composition of natural fiber, such as the cellulose content, structure of the fiber, angle of fibrils, cross section, and degree of polymerization determine the physical properties [7]. However, natural fibers, such as hemp, kenaf, flax, bamboo, coir, cotton, and banana, are not naturally compatible with hydrophobic thermoplastics, such as polypropylene (PP), polyethylene (PE), polyamide, polystyrene, low-density polyethylene (LDPE), high-density polyethylene (HDPE), and thermosets, such as epoxy, urea formaldehyde, phenol formaldehyde, and certain polyesters, due to the hydrophilic nature of the polymer. Hence, weak interfacial adhesion is produced between the reinforcing fiber and the polymer matrix. The compatibility between the fibers and the polymer can be improved through fiber surface modification, incorporation of compatibilizer, and matrix modification. Surface modification of natural fibers includes silanization [8, 9], alkalization [1,9-11], and acetylation [12]. 
TABLE 1: Chemical composition and moisture content of some vegetable fibers [16, 17].

\begin{tabular}{|c|c|c|c|c|c|c|}
\hline Fiber & $\begin{array}{c}\text { Cellulose } \\
\text { (wt.\%) }\end{array}$ & $\begin{array}{l}\text { Hemicellulose } \\
\text { (wt.\%) }\end{array}$ & Lignin (wt.\%) & Pectin (wt.\%) & Waxes (wt.\%) & $\begin{array}{c}\text { Moisture content } \\
\text { (wt.\%) }\end{array}$ \\
\hline Hemp & $70-74$ & $17.9-22.4$ & $3.7-5.7$ & 0.9 & 0.8 & $6.2-12$ \\
\hline Flax & 71 & $18.6-20.6$ & 2.2 & 2.3 & 1.7 & $8-12$ \\
\hline Kenaf & 45.57 & 21.5 & $8-13$ & $3-5$ & - & - \\
\hline Sisal & $66-78$ & $10-14$ & $10-14$ & 10 & 2 & $10-22$ \\
\hline Jute & $61-71.5$ & $13.6-20.4$ & $12-13$ & 0.2 & 0.5 & $12.5-13.7$ \\
\hline Ramie & $68.6-76.2$ & $13.1-16.7$ & $0.6-0.7$ & 1.9 & 0.3 & 7.5-17 \\
\hline Banana & 63-64 & 10 & 5 & - & - & $10-12$ \\
\hline Coir & $32-43$ & $0.15-0.25$ & $40-45$ & $3-4$ & - & 8 \\
\hline Cotton & $85-90$ & 5.7 & - & $0-1$ & 0.6 & $7.85-8.5$ \\
\hline
\end{tabular}

TABLE 2: Mechanical properties of some natural fibers when compared with conventional E-glass.

\begin{tabular}{|c|c|c|c|c|c|}
\hline Fibers & Density $\left(\mathrm{g} / \mathrm{cm}^{3}\right)$ & $\begin{array}{c}\text { Tensile strength } \\
(\mathrm{MPa})\end{array}$ & $\begin{array}{c}\text { Young's } \\
\text { modulus (GPa) }\end{array}$ & $\begin{array}{c}\text { Elongation-at- } \\
\text { break } \\
(\%)\end{array}$ & Reference \\
\hline Hemp & 1.14 & 690 & $30-60$ & 1.6 & {$[18]$} \\
\hline Jute & $1.3-1.45$ & $393-773$ & $13-26.5$ & $1.16-1.5$ & [19] \\
\hline Flax & 1.50 & $345-1100$ & 27.6 & $2.7-3.2$ & [19] \\
\hline Pineapple & 1.56 & 170 & 62 & - & {$[20]$} \\
\hline Cotton & 1.51 & 400 & 12 & $3-10$ & {$[21]$} \\
\hline Coir & 1.25 & 220 & 6 & $15-25$ & {$[21]$} \\
\hline Sisal & 1.33 & $600-700$ & 38 & $2-3$ & {$[21]$} \\
\hline E-glass & 2.5 & $2000-3500$ & 70 & 2.5 & {$[18,19]$} \\
\hline S-glass & 2.5 & 4570 & 86.0 & 2.8 & [19] \\
\hline Carbon (standard) & 1.4 & 4000 & $230-240$ & $1.4-1.8$ & [19] \\
\hline
\end{tabular}

Alkalization is the most widely used method of the abovementioned treatments because it is economical for fiber surface modification [13]. The treatment removes substances, such as hemicellulose, pectin, wax, lignin, and impurities covering the cellulose fibrils. This gives rise to a stronger interfacial interaction between the fiber and the polymer, leading to improved interfacial adhesion between the fiber and the polymer matrix.

Maleic anhydride grafted polypropylene (MAPP) is one of the widely used compatibilizers because of its effectiveness as a strong crosslinking agent in natural fiber-polymer composites $[14,15]$. A good adhesion or entanglement is achieved, when the PP chain in the compatibilizer diffuses into the polypropylene matrix. This process improves the interfacial adhesion between the fiber and the polymer matrix as a result of the longer $\mathrm{C}-\mathrm{C}$ chains. The effects of fiber modification, incorporation of MAPP, and nanoclay inclusion on the mechanical properties, thermal stability, and water absorption of sisal fiber (SF) reinforced recycled polypropylene (rPP) nanocomposites are evaluated in the current study.

\section{Materials and Methods}

2.1. Materials. Sisal fiber was supplied by CSIR, Port Elizabeth, South Africa. The fiber was treated with 5\% sodium hydroxide $(\mathrm{NaOH})$ solution in an oven for 2 hours at $70^{\circ} \mathrm{C}$.
The fiber was placed under running water for 12 hours and washed with $1 \%$ acetic acid solution in order to remove residual alkali. The fiber was left to dry at room temperature overnight and finally dried in an oven for 24 hours at $60^{\circ} \mathrm{C}$ (see Figure 1). The fiber was cut into an approximate length of $5 \mathrm{~mm}$. The recycled polypropylene was supplied by Transpaco Polymer Recycling. Maleic anhydride grafted polypropylene (MAPP, Fusabond ${ }^{\circledR P}$ MZ 109D, DuPont) was supplied by Chemical Innovation Co., Ltd. Nanoclay (organically modified montmorillonites, Cloisite ${ }^{\circledR 30 B}$ ) was supplied by Southern Clay Products Inc., USA.

2.2. Composite Preparation. The sisal fiber, rPP, and the nanoclay were dried in a vacuum oven $60^{\circ} \mathrm{C}$ for 4 hours in order to ensure all absorbed moisture, which may lead to void formation during processing, was removed. The materials were later placed in a desiccator to cool before processing. The compounding was carried out using HAAKE PolyLab OS Rheomix batch mixer (Thermo Electron Co., USA), operated at a temperature of $200^{\circ} \mathrm{C}$ (set temperature) and rotor speed of $60 \mathrm{rpm}$, for $8 \mathrm{~min}$. In the first stage, SF/rPP composites containing $40 \mathrm{wt} . \%$ treated and untreated fibers were prepared. In the second stage, composites containing $40 \mathrm{wt} . \%$ treated sisal fiber, 5 wt.\% MAPP, and varying nanoclay (C1, C3, and C5, i.e., 1, 3, and 5 wt.\% loading, resp.) were prepared. Neat rPP was also prepared (as reference) for the sake of comparison. 


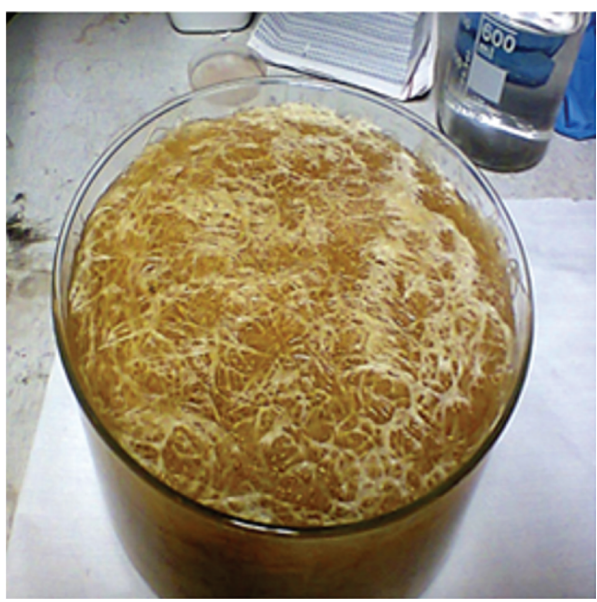

(a)

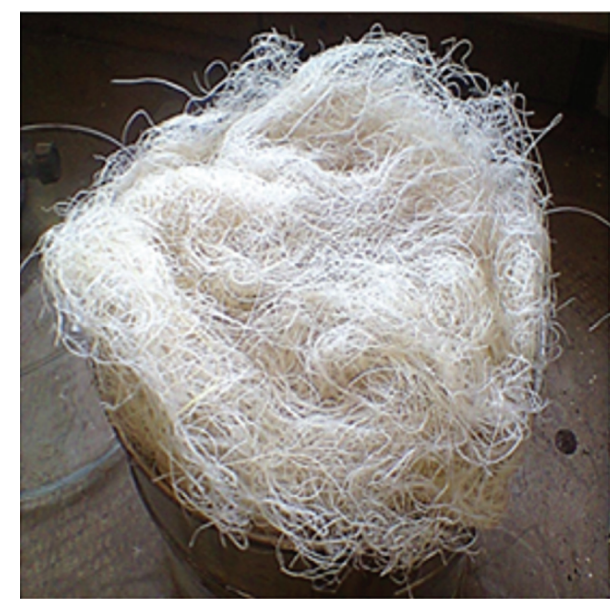

(b)

FIgURE 1: Pictorial images of surface modification of sisal fiber: (a) during treatment and (b) after treatment and cleaning/washing.

TABLE 3: Sample name and the various compositions of SF/rPP composites.

\begin{tabular}{lcccc}
\hline Samples & rPP (wt.\%) & $\begin{array}{c}\text { Sisal } \\
\text { (wt.\%) }\end{array}$ & $\begin{array}{c}\text { MAPP } \\
\text { (wt.\%) }\end{array}$ & $\begin{array}{c}\text { Nanoclay } \\
\text { (wt.\%) }\end{array}$ \\
\hline rPP & 100 & - & - & - \\
$\mathrm{UT} / \mathrm{rPP}$ & 60 & 40 & - & - \\
$\mathrm{T} / \mathrm{rPP}$ & 60 & 40 & - & - \\
$\mathrm{T} / \mathrm{MAPP} / \mathrm{rPP}$ & 55 & 40 & 5 & - \\
$\mathrm{T} / \mathrm{MAPP} / \mathrm{C} 1 / \mathrm{rPP}$ & 54 & 40 & 5 & 1 \\
T/MAPP/C3/rPP & 52 & 40 & 5 & 3 \\
T/MAPP/C5/rPP & 50 & 40 & 5 & 5 \\
\hline
\end{tabular}

UT: untreated fiber, T: treated fiber, C1: 1 wt.\% clay, C3: 3 wt.\% clay, and C5: $5 \mathrm{wt} . \%$ clay inclusions.

The premixed samples were compression-moulded using a Carver laboratory press at $200^{\circ} \mathrm{C}$ for both plates under a pressure of approximately $10.43 \mathrm{MPa}$ for a total processing time of $8 \mathrm{~min}$ and subsequently allowed to cool to room temperature. Table 3 shows the compositions of the composites prepared.

\section{Characterization}

3.1. Fourier Transform Infrared (FTIR) Spectroscopy. Fourier transform infrared (FTIR) spectroscopy was performed on the samples using a PerkinElmer Spectrum 100 spectrometer (PerkinElmer, USA) between 500 and $4000 \mathrm{~cm}^{-1}$ wave number. The chemical variations of the polypropylene, fiber, and nanoclay were validated by FTIR analysis.

3.2. Mechanical Properties. Tensile properties were determined using an Instron 5966 tester (Instron Engineering Corporation, USA), according to ASTM D638 with a load cell of $10 \mathrm{kN}$, at a single strain rate of $5 \mathrm{~mm} / \mathrm{min}$ at room temperature. The results are the average of five different tests per samples. Notched Izod impact testing was done using CEAST Pendulum Resil Impactor II (Italy) with a notch depth of $2.5 \mathrm{~mm}$ and a notch angle of $45^{\circ}$, as per ISO 179 standard in order to determine the toughness of the material. The results presented here are the average of four different tests per samples.

3.3. Scanning Electron Microscope (SEM). The cryogenically fractured surface morphology of the samples was studied using a scanning electron microscope (JEOL JSM-7500F, Germany). Compression-moulded samples were cryogenically fractured in liquid nitrogen, mounted on aluminium stubs, and coated with gold using an EMITECH K950X sputter coater. The fractured surface image was then captured in order to study the material morphology.

3.4. Thermal Analyses. The thermal stability of rPP and $\mathrm{SF} / \mathrm{rPP}$ composites was carried out using a thermogravimetric analyzer (TGA; TA Instrument, Model Q500, USA). A constant heating rate of $10^{\circ} \mathrm{C} / \mathrm{min}$ from room temperature to $700^{\circ} \mathrm{C}$ was maintained under air flow. An approximate weight of $5 \mathrm{mg}$ was used for each sample.

3.5. Water Absorption. The water absorption was studied by complete immersion of the samples in water at room temperature. The samples were placed in water after measuring the initial weight. The immersed composites were removed from the water at a constant time interval of 1 hour. The percentage increase in weight was calculated using

$$
\text { Water absorption }(\%)=\left(\frac{W_{f}-W_{i}}{W_{i}}\right) \times 100,
$$

where $W_{i}$ is the initial weight before immersion and $W_{f}$ is the final weight after immersion.

\section{Results and Discussion}

4.1. FTIR Analysis of All Composites. The sisal fiber reinforced recycled polypropylene composites and neat rPP were subjected to FTIR analysis and the results are shown in Figure 2. 


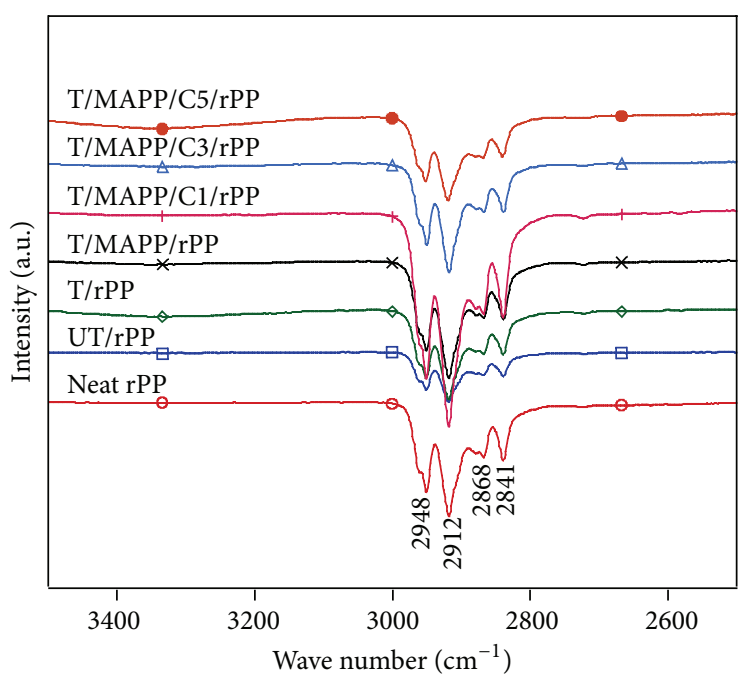

(a)

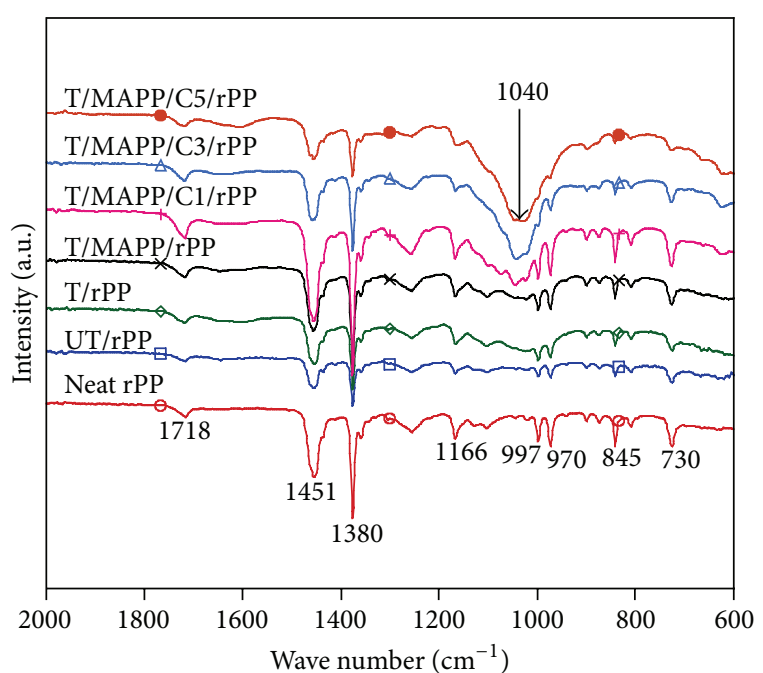

(b)

FIGURE 2: FTIR analysis of neat rPP and $40 \mathrm{wt} . \%$ sisal fiber and nanoclay reinforced polypropylene composites.

Similar spectral patterns were observed with the neat recycled polypropylene and the untreated SF/rPP composites. The following peaks were observed and explained in a previous research by the same authors: 2948, 2912, 2868, 2841, 1718, 1451,1380 , and $1166 \mathrm{~cm}^{-1}$ [22]. The treatment of fiber led to increasing spectral intensity at $1020 \mathrm{~cm}^{-1}$ as a result of C$\mathrm{N}$ stretch (aliphatic amines) due to the hydroxyl group of cellulose which was exposed by the fiber treatment. Incorporation of MAPP resulted in the broadening of the peak (C$\mathrm{N}$ stretch) at $1040 \mathrm{~cm}^{-1}$, indicating the chemical interaction between the fiber, MAPP, and the polymer. The spectral intensity became more pronounced with the incorporation of nanoclay. Further increase in nanoclay showed an increase in spectral intensity and was maintained for the 3 and $5 \mathrm{wt} . \%$ nanoclay contents. The effective interaction between the fiber, MAPP, nanoclay, and recycled polypropylene was observed to improve the mechanical properties as will be discussed later.

4.2. Mechanical Properties. The tensile strength and tensile modulus of sisal fiber (untreated and treated) and nanoclay reinforced polypropylene composites are shown in Figure 3 and Table 4. Sisal fiber surface modification showed a slight improvement in these properties. The treatment resulted in a decrease in the diameter of the fiber, resulting in smaller cross-sectional area (see (2)). Incorporation of $1 \mathrm{wt} . \%$ nanoclay led to 52.95 and $13.67 \%$ increase in tensile strength and tensile modulus, respectively, when compared to the untreated sisal fiber/rPP composite. Chanprapanon et al. [23] reported that the incorporation of $1 \mathrm{wt} . \%$ nanoclay slightly increased the tensile strength and tensile modulus of SF/PP composites. Further increase in nanoclay content showed further improvement in strength [24]. This is due to adequate dispersion of the nanoclay in the fiber and the polymer matrix. In general, fiber surface modification and nanoclay, incorporated into polypropylene matrix, showed significant improvements in tensile strength and tensile modulus of
$\mathrm{SF} / \mathrm{rPP}$ nanocomposites. Incorporation of $5 \mathrm{wt} . \%$ nanoclay showed the optimal result for the tensile strength and tensile modulus of $55.95 \pm 1.58$ and $1700.3 \pm 169.05 \mathrm{MPa}$, respectively. Lee et al. [24] also stated that clay content $\leq 5 \%$ gives better result when used as fillers in composites.

The notched impact strength of sisal fiber (untreated and treated) and nanoclay reinforced polypropylene composites are illustrated in Figure 4. Fiber treatment led to $3.14 \%$ improvement and incorporation of $1 \mathrm{wt} . \%$ clay reduced impact strength to $7.98 \mathrm{KJ} / \mathrm{m}^{2}$ when compared to the untreated $\mathrm{SF} / \mathrm{rPP}$ composite of $8.28 \mathrm{KJ} / \mathrm{m}^{2}$. The impact strength was observed to increase with the incorporation of 5 wt. $\%$ nanoclay to $8.76 \pm 0.64 \mathrm{KJ} / \mathrm{m}^{2}$ :

$$
\begin{aligned}
& A=\frac{\pi D}{4}, \\
& \delta=\frac{P}{A},
\end{aligned}
$$

where $\delta(\mathrm{MPa})$ is the tensile strength, $P(\mathrm{~N})$ is the maximum applied load, $A\left(\mathrm{~m}^{2}\right)$ is the cross-sectional area, and $D(\mathrm{~m})$ is the diameter of the fiber.

4.3. Scanning Electron Microscopy (SEM). The SEM image in Figures 5(a) and 5(b) shows the morphology of the fractured surfaces of untreated and treated fiber $\mathrm{SF} / \mathrm{rPP}$ composites. The surface treatment and incorporation of MAPP and nanoclay improved the interfacial adhesion between the fiber and the polymer matrix as shown in Figures 5(b)-5(f). There were traces of cracks in the untreated SF/rPP composites as observed in Figure 5(a); this implies poor interfacial bonding between the untreated sisal fiber and the recycled polypropylene matrix. The treated SF/rPP composites show no sign of crack or void on the fractured surface of the composites. The incorporation of MAPP and nanoclay further enhanced the interfacial adhesion, eliminating any possible crack or microvoids in the fracture surface of the composites. 

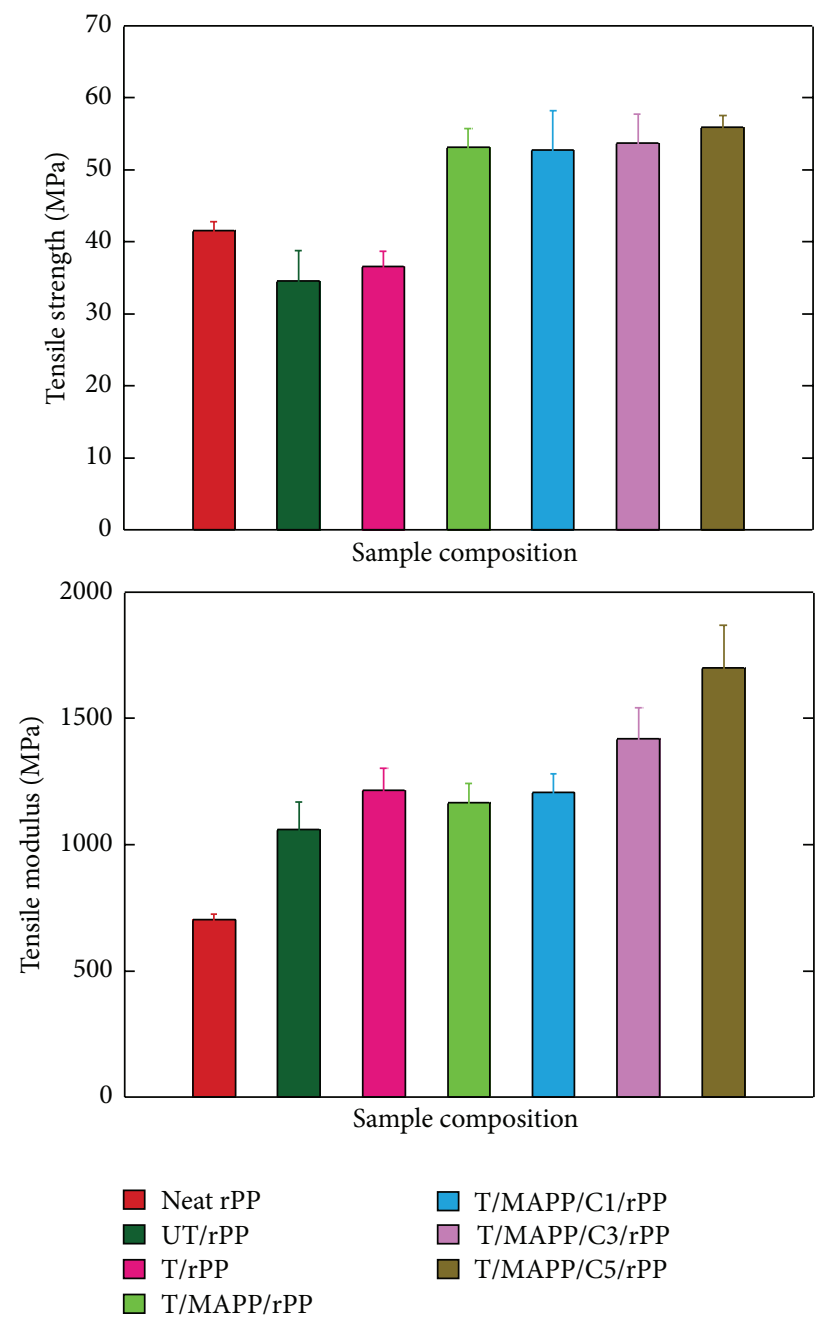

Figure 3: Tensile strength and tensile modulus of sisal fiber and nanoclay reinforced polypropylene composites.

This further validates the improvement observed in the mechanical properties due to the removal of hemicellulose, dirt, and wax which resulted in a stronger interfacial adhesion between the sisal fiber and polypropylene matrix.

4.4. Thermal Analyses. Figures 6 and 7 show the TGA weight loss and derivative weight loss (DTG) curves of samples containing $40 \mathrm{wt} . \%$ sisal fibers. The temperatures at 5\% weight loss $\left(T_{5 \%}\right), 10 \%$ weight loss $\left(T_{10 \%}\right)$, the maximum decomposition temperature $\left(T_{\mathrm{Max}}\right)$, and percentage of char residue at $500^{\circ} \mathrm{C}$ are also shown in Table 5. From Figure 6, lower thermal stability was observed with the composites containing treated fiber and MAPP when compared to the untreated SF/rPP composites. This may be due to the removal of hemicellulose and lignin in the case of the treated sisal fiber. The incorporation of nanoclay further improved the thermal stability as shown in Table 5. Although it has been widely reported in literature that inorganic fillers incorporated into polymer matrix help to improve the thermal stability of the system by absorbing and dissipating the heat energy entering the material [25-27], there was an increase with further

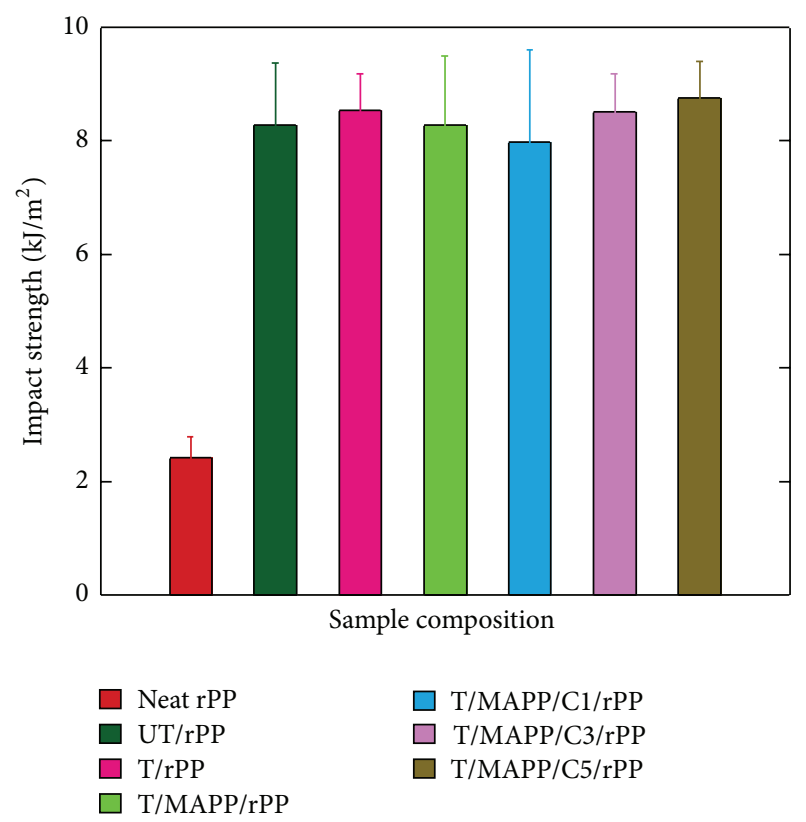

FIGURE 4: Impact strength of sisal fiber and nanoclay reinforced polypropylene composites.

increase in the nanoclay contents. The $5 \mathrm{wt} . \%$ nanoclay loading in SF/rPP composites produced higher char (residue) when compared with other composites.

4.5. Water Absorption. Figure 8 shows the influence of fiber treatment and incorporation of MAPP and nanoclay on water absorption of SF/rPP composites. Very little water was absorbed by neat rPP during the immersion time due to the hydrophobic character of rPP. Higher water absorption was observed with SF/rPP composites due to the hydrophilic nature of natural fibers [28]. The surface modification of sisal fiber and incorporation of MAPP and nanoclay showed reduced water absorption for the $\mathrm{SF} / \mathrm{rPP}$ composites as seen in Figure 8. The presence of lignin, hemicellulose, and wax in the fiber was responsible for the high level of water absorption of $\mathrm{SF} / \mathrm{rPP}$ composites; these were reduced by alkalization; similar result was reported by Kaewkuk et al. [1]. The strong adhesion between the fiber and the polymer matrix caused by the fiber modification and MAPP and nanoclay inclusion reduced the water absorption capacity of the composites. The nanoclay functions as a water barrier medium in the composite, slowing down the rate of water absorption. Mohan and Kanny [11] reported similar phenomenon. The composite with treated fiber showed the least water absorption among all the composites after 3 hours' immersion time.

\section{Conclusions}

The study focused on the effect of sisal fiber surface modification and nanoclay inclusion, in order to improve mechanical properties of SF/rPP nanocomposites. The fiber was treated with $5 \%$ sodium hydroxide solution and the nanoclay was varied from 1 and 3 to $5 \mathrm{wt} . \%$. There was a slight improvement in the mechanical properties of treated SF/rPP composites. 


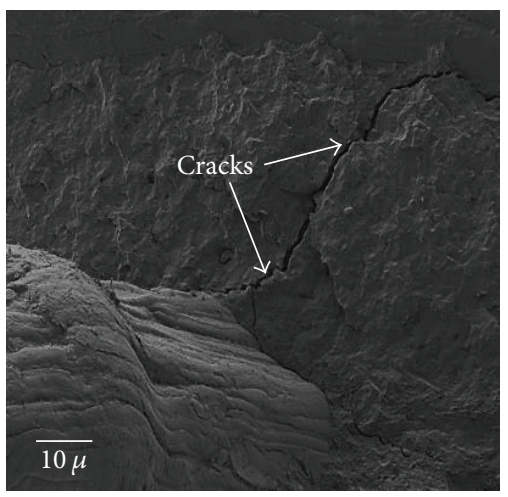

(a)

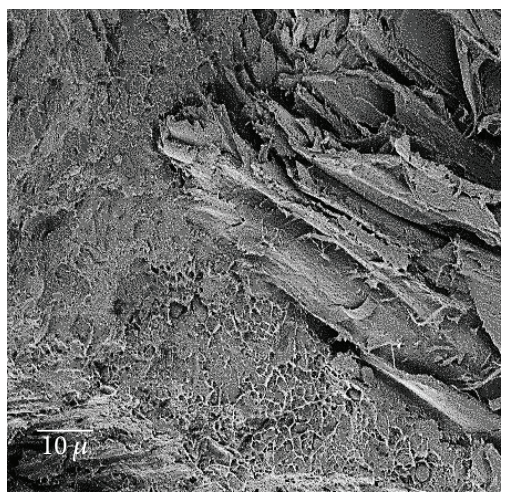

(d)

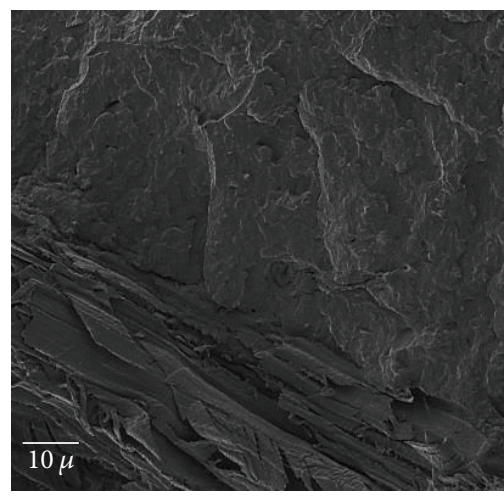

(b)

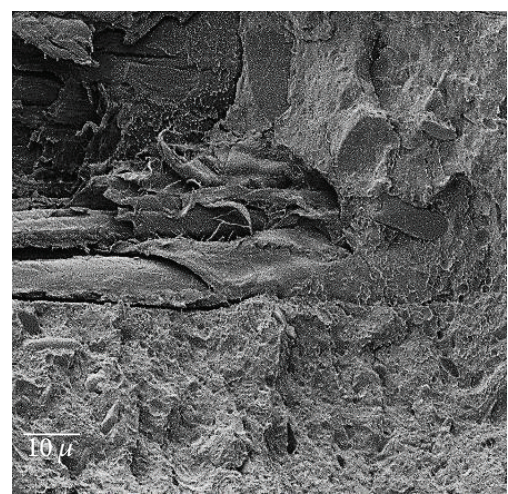

(e)

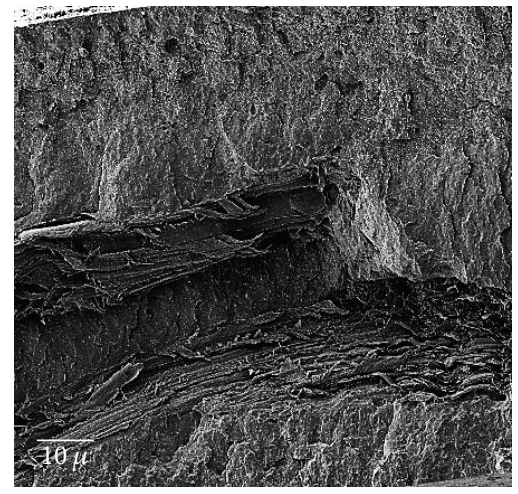

(c)

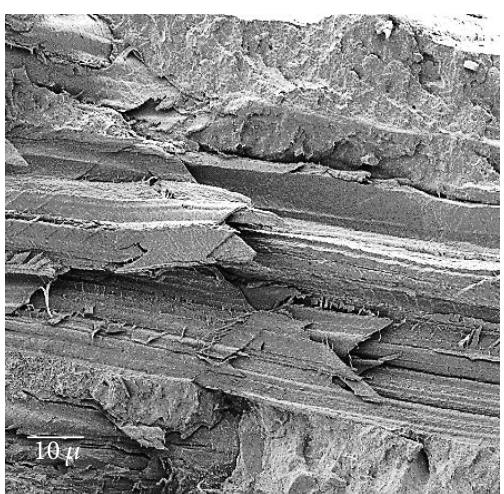

(f)

FIGURE 5: SEM image of cryogenically fracture surface of treated (a) UT/rPP, (b) T/rPP, (c) T/MAPP/rPP, (d) T/MAPP/Cl/rPP, (e) T/MAPP/C3/rPP, and (f) T/MAPP/C5/rPP, composites.

TABLE 4: Mechanical properties of rPP composites.

\begin{tabular}{|c|c|c|c|c|c|c|}
\hline Samples & Tensile strength $(\mathrm{MPa})$ & $\mathrm{SD}^{*}$ & Tensile modulus (MPa) & $\mathrm{SD}^{*}$ & Impact strength $\left(\mathrm{KJ} / \mathrm{m}^{2}\right)$ & $\mathrm{SD}^{*}$ \\
\hline rPP & 41.54 & 1.23 & 705.0 & 20.068 & 2.42 & 0.36 \\
\hline $\mathrm{UT} / \mathrm{rPP}$ & 34.54 & 4.29 & 1060.6 & 107.45 & 8.28 & 1.10 \\
\hline $\mathrm{T} / \mathrm{rPP}$ & 36.54 & 2.14 & 1214.6 & 88.411 & 8.54 & 0.65 \\
\hline T/MAPP/rPP & 53.10 & 2.61 & 1164.9 & 75.619 & 8.29 & 1.20 \\
\hline T/MAPP/C1/rPP & 52.83 & 5.31 & 1205.6 & 75.247 & 7.98 & 1.63 \\
\hline T/MAPP/C3/rPP & 53.70 & 4.03 & 1419.6 & 123.33 & 8.51 & 0.68 \\
\hline T/MAPP/C5/rPP & 55.95 & 1.58 & 1700.3 & 169.05 & 8.76 & 0.64 \\
\hline
\end{tabular}

$\mathrm{SD}^{*}:$ standard deviation.

TABle 5: Thermal properties of SF/rPP composites.

\begin{tabular}{lccccc}
\hline Samples & $T_{5 \%}\left({ }^{\circ} \mathrm{C}\right)$ & $T_{10 \%}\left({ }^{\circ} \mathrm{C}\right)$ & $T_{\text {Max }}\left({ }^{\circ} \mathrm{C}\right)$ & \% Weight remaining at $T_{\text {Max }}$ & Residue at $500^{\circ} \mathrm{C}$ \\
\hline Neat rPP & 301.88 & 323.01 & 379.79 & 37.85 & 4.044 \\
UT40/rPP & 274.45 & 293.70 & 370.90 & 33.02 & 3.413 \\
T40/rPP & 271.30 & 294.69 & 351.97 & 51.54 & 3.327 \\
T40/MAPP/rPP & 262.64 & 281.83 & 350.39 & 44.70 & 2.943 \\
T40/MAPP/C1/rPP & 262.80 & 285.75 & 351.89 & 45.91 & 4.748 \\
T40/MAPP/C3/rPP & 265.76 & 288.27 & 352.54 & 45.91 & 8.919 \\
T40/MAPP/C5/rPP & 282.11 & 306.87 & 394.14 & 36.64 & 16.83 \\
\hline
\end{tabular}




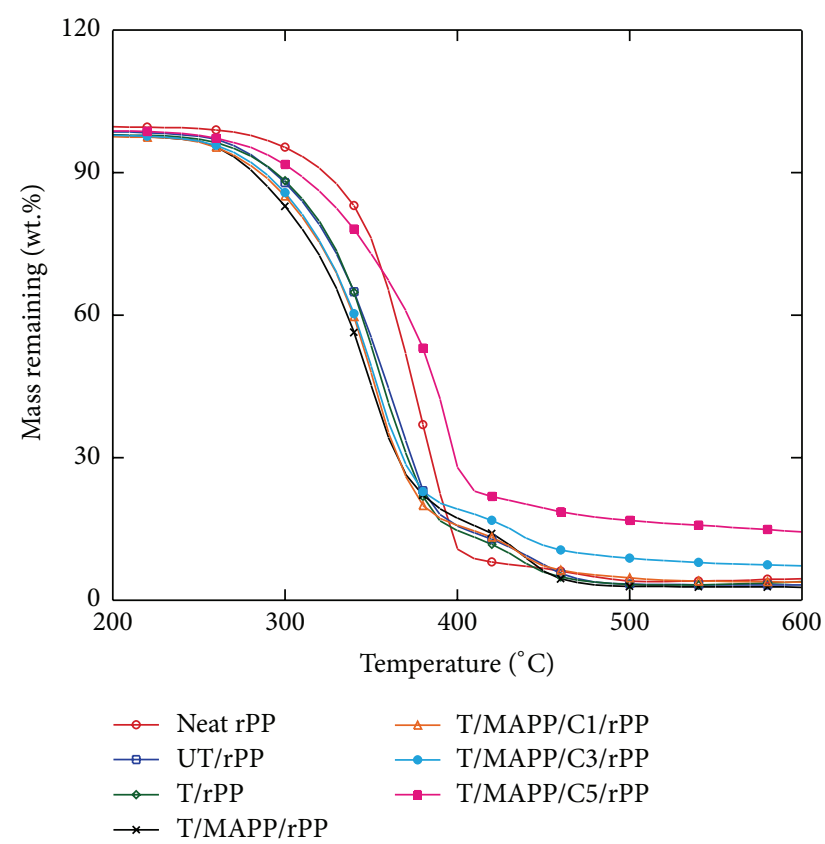

FIGURE 6: Effect of fiber treatment and nanoclay on TGA curves of $\mathrm{rPP}$ and SF/rPP composites.

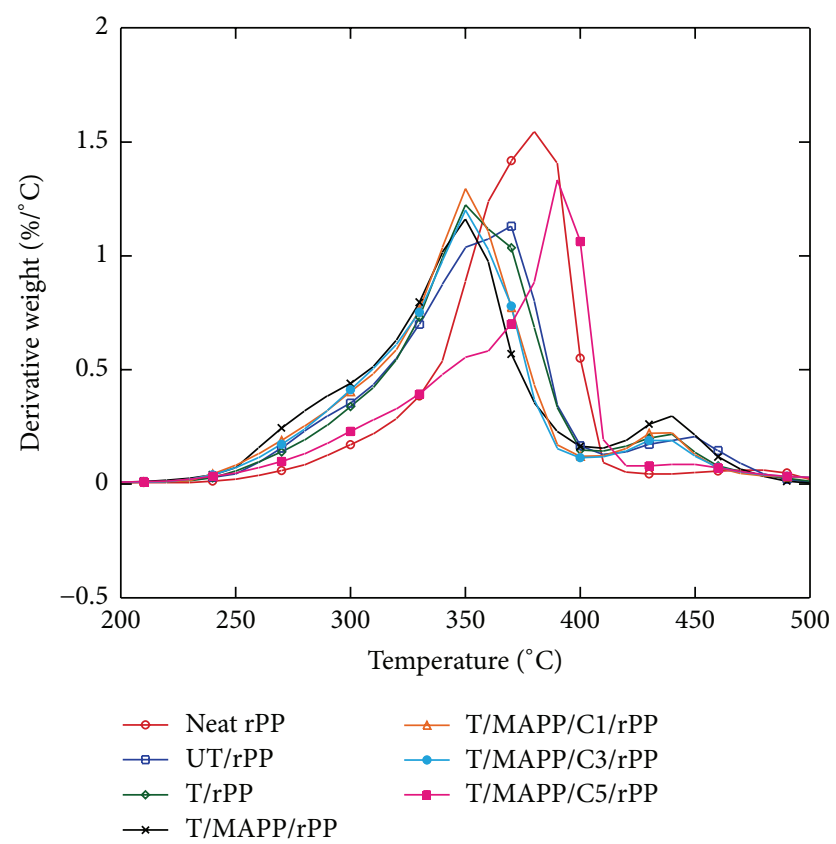

FIGURE 7: Effect of fiber treatment and nanoclay on DTG curves of $\mathrm{rPP}$ and SF/rPP composites.

The incorporation of $5 \mathrm{wt} . \%$ MAPP and nanoclay inclusion showed significant improvement in the mechanical properties of SF/rPP composites. With increasing nanoclay content, tensile strength, tensile modulus, and impact strength of the $\mathrm{SF} / \mathrm{rPP}$ composites increased. Optimal values of the tensile strength, tensile modulus, and impact strength of 32.80, 37.62, and $5.48 \%$, respectively, were observed with 40 wt. $\%$ treated fibers, 5 wt. $\%$ MAPP, and 5 wt.\% nanoclay, when compared to

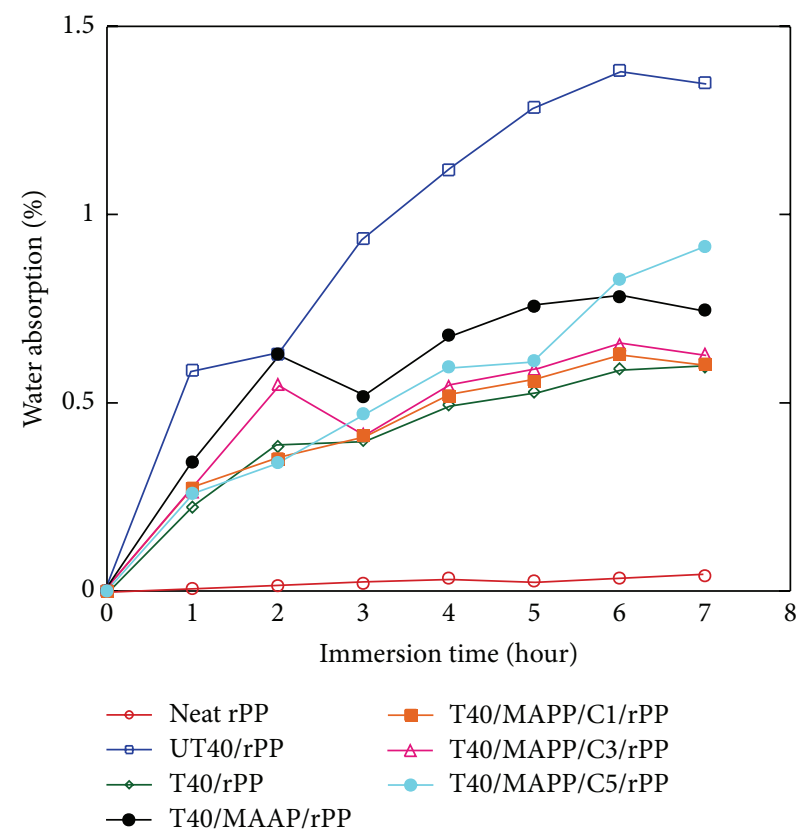

FIGURE 8: Effect of fiber treatment and nanoclay on sisal fiber/polypropylene composites.

untreated SF/rPP composites. The fiber surface modification enhanced the interfacial adhesion between the fiber and polymer matrix, which was revealed in the SEM images morphology.

Thermal stability was reduced due to the addition of sisal fiber to the polymer. Incorporation of MAPP and nanoclay improved the thermal stability and higher amount of char residue was produced. As clay content increased from 1 to $5 \mathrm{wt} . \%$, the thermal stability was also increased, which is a result of the clay content. Clay is an excellent insulating material and, when combined with polymers, it improves the composite thermal stability. The nanocomposite silicate layers hold accumulated heat that is generated within or externally, which will, otherwise, lead to accelerated decomposition [29].

Natural fibers are known to rapidly increase water absorption of fiber/polymer matrix composites, due to the hydrophilic character of natural fibers. However, there was a significant decrease in water absorption of composites containing treated fiber and nanoclay. The nanoclay acted as water barrier medium in the composites, slowing down the rate of water absorption, hence contributing positively to the improved rate of water absorption experienced by the composites $[11,30]$. It was also observed that increasing immersion time led to increasing water absorption of the SF/rPP composites.

\section{Competing Interests}

The authors declare that there is no conflict of interests.

\section{Acknowledgments}

The authors would like to thank the Tshwane University of Technology Pretoria for providing the platform to carry 
out this research work. Also, they wish to acknowledge the National Research Foundation (NRF), South Africa, for providing the funding for this research (Grant no. 98760). In addition, they are thankful to Mr. Fred G. Molelekwa for sourcing the recycled polypropylene.

\section{References}

[1] S. Kaewkuk, W. Sutapun, and K. Jarukumjorn, "Effects of interfacial modification and fiber content on physical properties of sisal fiber/polypropylene composites," Composites Part B: Engineering, vol. 45, no. 1, pp. 544-549, 2013.

[2] R. Ali, S. Iannace, and L. Nicolais, "Effect of processing conditions on mechanical and viscoelastic properties of biocomposites," Journal of Applied Polymer Science, vol. 88, no. 7, pp. 16371642, 2003.

[3] C. Klason, J. Kubat, and P. Gatenholm, "Wood fiber reinforced composites," in Viscoelasticity of Biomaterials, W. G. Glasser and H. Hatakeyama, Eds., American Society, Washington, DC, USA, 1992.

[4] V. G. Geethamma, K. T. Mathew, R. Lakshminarayanan, and S. Thomas, "Composite of short coir fibres and natural rubber: effect of chemical modification, loading and orientation of fibre," Polymer, vol. 39, no. 6-7, pp. 1483-1491, 1998.

[5] K. Joseph, S. Varghese, G. Kalaprasad et al., "Influence of interfacial adhesion on the mechanical properties and fracture behaviour of short sisal fibre reinforced polymer composites," European Polymer Journal, vol. 32, no. 10, pp. 1243-1250, 1996.

[6] A. Bessadok, S. Marais, S. Roudesli, C. Lixon, and M. Métayer, "Influence of chemical modifications on water-sorption and mechanical properties of Agave fibres," Composites Part A: Applied Science and Manufacturing, vol. 39, no. 1, pp. 29-45, 2008.

[7] A. K. Bledzki and J. Gassan, "Composites reinforced with cellulose based fibres," Progress in Polymer Science, vol. 24, no. 2, pp. 221-274, 1999.

[8] M. Z. Rong, M. Q. Zhang, Y. Liu, G. C. Yang, and H. M. Zeng, "The effect of fiber treatment on the mechanical properties of unidirectional sisal-reinforced epoxy composites," Composites Science and Technology, vol. 61, no. 10, pp. 1437-1447, 2001.

[9] P. A. Sreekumar, S. P. Thomas, J. M. Saiter, K. Joseph, G. Unnikrishnan, and S. Thomas, "Effect of fiber surface modification on the mechanical and water absorption characteristics of sisal/polyester composites fabricated by resin transfer molding," Composites Part A: Applied Science and Manufacturing, vol. 40, no. 11, pp. 1777-1784, 2009.

[10] S. K. Nayak, G. Dixit, and K. K. Appukuttan, "Sisal fiber (SF) reinforced recycled polypropylene (RPP) composites," International Journal of Plastics Technology, vol. 16, no. 2, pp. 150-165, 2012.

[11] T. P. Mohan and K. Kanny, "Chemical treatment of sisal fiber using alkali and clay method," Composites Part A: Applied Science and Manufacturing, vol. 43, no. 11, pp. 1989-1998, 2012.

[12] C. Albano, J. González, M. Ichazo, and D. Kaiser, “Thermal stability of blends of polyolefins and sisal fiber," Polymer Degradation and Stability, vol. 66, no. 2, pp. 179-190, 1999.

[13] V. A. Alvarez and A. Vázquez, "Influence of fiber chemical modification procedure on the mechanical properties and water absorption of MaterBi-Y/sisal fiber composites," Composites Part A: Applied Science and Manufacturing, vol. 37, no. 10, pp. 1672-1680, 2006.
[14] U. Hujuri, S. K. Chattopadhay, R. Uppaluri, and A. K. Ghoshal, "Effect of maleic anhydride grafted polypropylene on the mechanical and morphological properties of chemically modified short-pineapple-leaf-fiber-reinforced polypropylene composites," Journal of Applied Polymer Science, vol. 107, no. 3, pp. 1507-1516, 2008.

[15] U. K. Dwivedi and N. Chand, "Influence of MA-g-PP on abrasive wear behaviour of chopped sisal fibre reinforced polypropylene composites," Journal of Materials Processing Technology, vol. 209, no. 12-13, pp. 5371-5375, 2009.

[16] K. M. Amar, M. Manjusri, and T. D. Lawrence, Natural Fibers, Biopolymers, and Bio-Composites, CRC Press/Taylor \& Francis, New York, NY, USA, 2005.

[17] A. Bismarck, S. Mishra, and T. Lampke, "Plant fibers as reinforcement for green composites," in Natural Fibers, Biopolymers, and Biocomposites, A. K. Mohanty, M. Misra, and L. T. Drzal, Eds., CRC Press, Boca Raton, Fla, USA, 2005.

[18] H. N. Dhakal, Z. Y. Zhang, and M. O. W. Richardson, "Effect of water absorption on the mechanical properties of hemp fibre reinforced unsaturated polyester composites," Composites Science and Technology, vol. 67, no. 7-8, pp. 1674-1683, 2007.

[19] A. K. Mohanty, M. Misra, and G. Hinrichsen, "Biofibres, biodegradable polymers and biocomposites: an overview," Macromolecular Materials and Engineering, vol. 276-277, no. 1, pp. 124,2000

[20] S. Taj, M. Ali, and S. Khan, "Natural fiber-reinforced polymer composites: review," Proceedings of the Pakistan Academy of Sciences, vol. 44, no. 2, pp. 129-144, 2007.

[21] R. Kozłowski and M. Władyka-Przybylak, "Flammability and fire resistance of composites reinforced by natural fibers," Polymers for Advanced Technologies, vol. 19, no. 6, pp. 446-453, 2008.

[22] I. D. Ibrahim, T. Jamiru, E. R. Sadiku, W. K. Kupolati, and S. C. Agwuncha, "Dependency of the mechanical properties of sisal fiber reinforced recycled polypropylene composites on fiber surface treatment, fiber content and nanoclay," Journal of Polymers and the Environment, 2016.

[23] W. Chanprapanon, N. Suppakarn, and K. Jarukumjorn, "Effect of organoclay types on mechanical properties and flammability of polypropylene/sisal fiber composites," in Proceedings of the 18th International Conference on Composite Materials (ICCM '11), Jeju Island, South Korea, August 2011.

[24] Y. H. Lee, T. Kuboki, C. B. Park, M. Sain, and M. Kontopoulou, "The effects of clay dispersion on the mechanical, physical, and flame-retarding properties of wood fiber/polyethylene/clay nanocomposites," Journal of Applied Polymer Science, vol. 118, no. 1, pp. 452-461, 2010.

[25] S. Y. Lee, I. A. Kang, G. H. Doh et al., “Thermal, mechanical and morphological properties of polypropylene/clay/wood flour nanocomposites," eXPRESS Polymer Letters, vol. 2, no. 2, pp. 7887,2008

[26] H. Alamri, I. M. Low, and Z. Alothman, "Mechanical, thermal and microstructural characteristics of cellulose fibre reinforced epoxy/organoclay nanocomposites," Composites Part B: Engineering, vol. 43, no. 7, pp. 2762-2771, 2012.

[27] N. R. Paluvai, S. Mohanty, and S. K. Nayak, "Studies on thermal degradation and flame retardant behavior of the sisal fiber reinforced unsaturated polyester toughened epoxy nanocomposites," Journal of Applied Polymer Science, vol. 132, no. 24, Article ID 42068, 2015.

[28] I. D. Ibrahim, T. Jamiru, E. R. Sadiku, W. K. Kupolati, S. C. Agwuncha, and G. Ekundayo, "Mechanical properties of 
sisal fibre-reinforced polymer composites: a review," Composite Interfaces, vol. 23, no. 1, pp. 15-36, 2016.

[29] M. Pannirselvam, Design, development, and characterization of polypropylene clay nanocomposites [M.Eng. thesis], RMIT University, Melbourne, Australia, 2008.

[30] A. G. Supri, H. Salmah, and K. Hazwan, "Low density polyethylene-nanoclay composites: the effect of poly(acrylic acid) on mechanical properties, XRD, morphology properties and water absorption," Malaysian Polymer Journal, vol. 3, no. 2, pp. 39-53, 2008. 

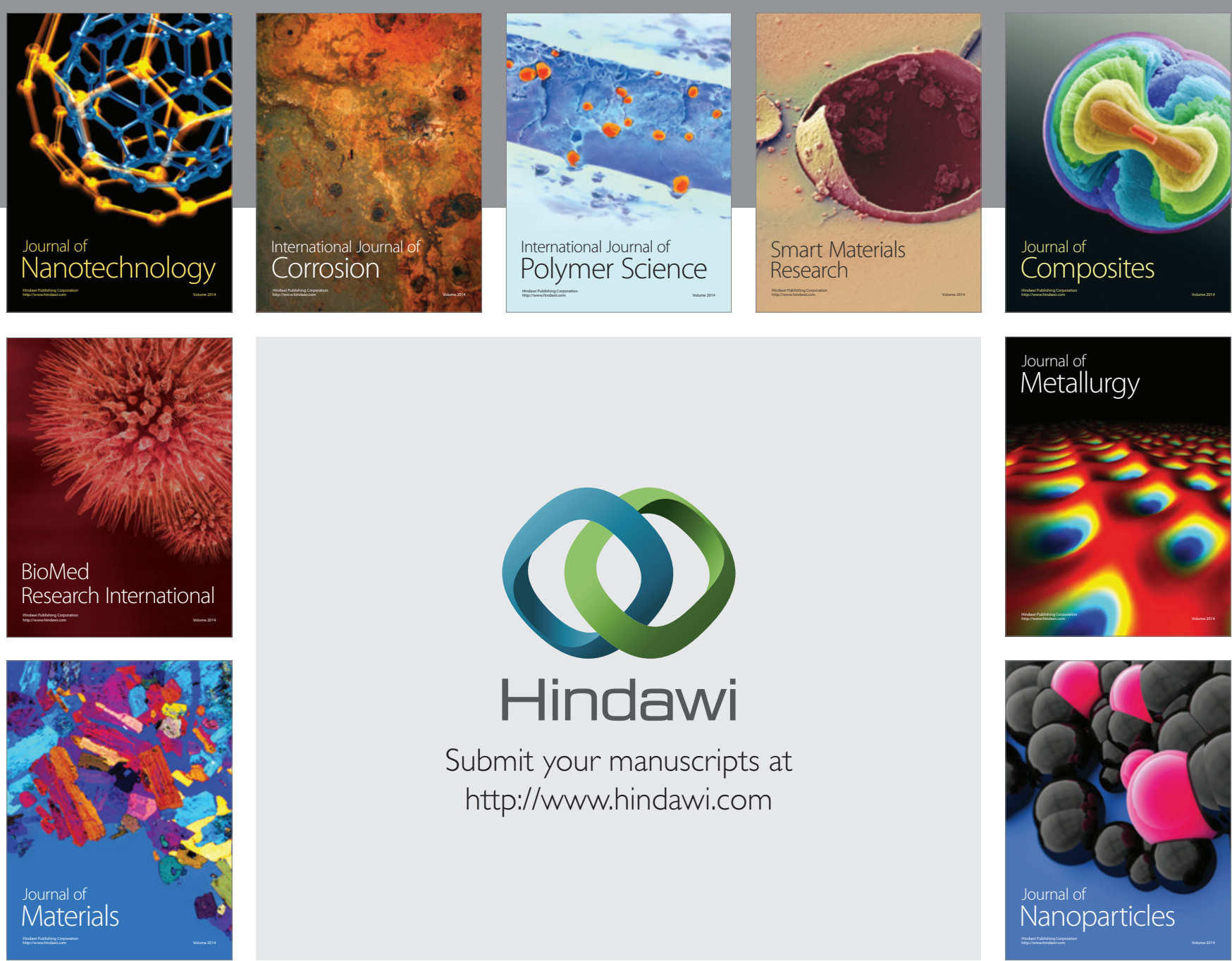

\section{Hindawi}

Submit your manuscripts at

http://www.hindawi.com

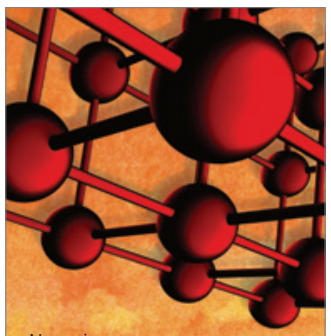

Materials Science and Engineering
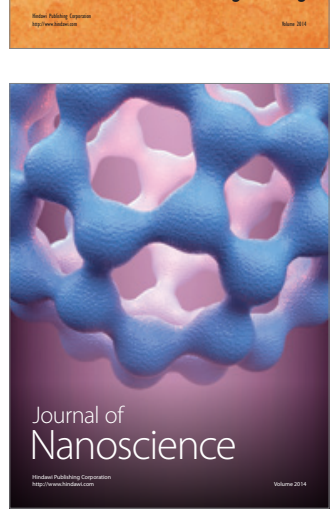
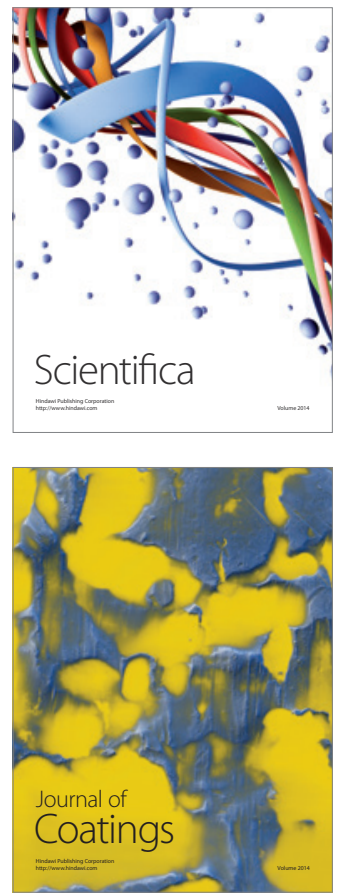
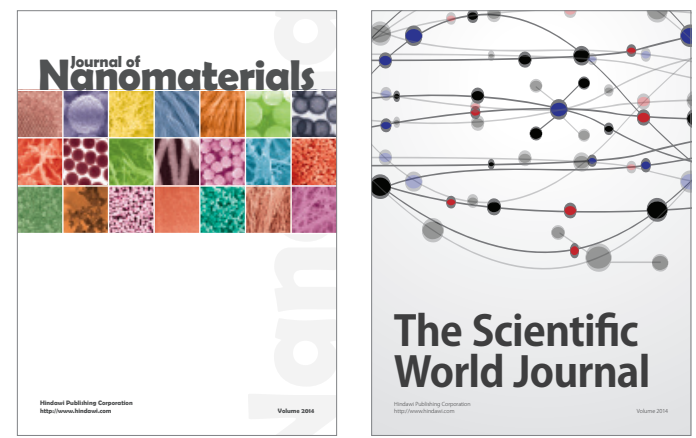

The Scientific World Journal
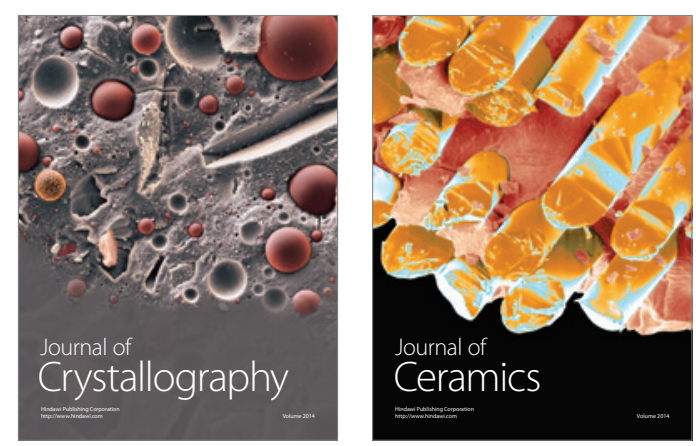
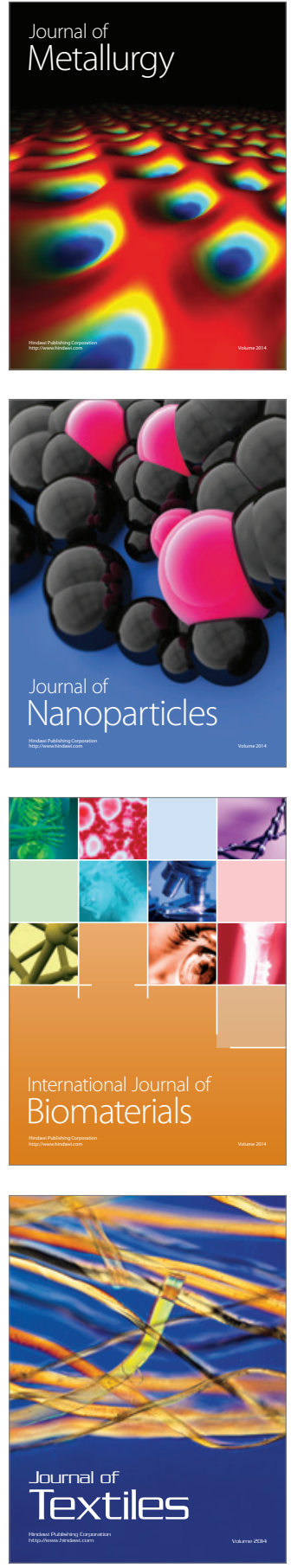